\title{
A case-control study on the effect of Apolipoprotein E genotypes on gastric cancer risk and progression
}

\author{
Emma De Feo ${ }^{1}$, Benedetto Simone ${ }^{1}$, Roberto Persiani ${ }^{2}$, Ferdinando Cananzi ${ }^{2}$, Alberto Biondi ${ }^{2}$, Dario Arzani ${ }^{1}$, \\ Rosarita Amore ${ }^{1}$, Domenico D'Ugo ${ }^{2}$, Gualtiero Ricciardi ${ }^{1}$ and Stefania Boccia ${ }^{1,3^{*}}$
}

\begin{abstract}
Background: Apolipoprotein E (ApoE) is a multifunctional protein playing both a key role in the metabolism of cholesterol and triglycerides, and in tissue repair and inflammation. The ApoE gene (19q13.2) has three major isoforms encoded by $\varepsilon 2, \varepsilon 3$ and $\varepsilon 4$ alleles with the $\varepsilon 4$ allele associated with hypercholesterolemia and the $\varepsilon 2$ allele with the opposite effect. An inverse relationship between cholesterol levels and gastric cancer (GC) has been previously reported, although the relationship between apoE genotypes and GC has not been explored so far.

Methods: One hundred and fifty-six gastric cancer cases and 444 hospital controls were genotyped for apoE polymorphism ( $\varepsilon 2, \varepsilon 3, \varepsilon 4$ alleles). The relationship between GC and putative risk factors was measured using the adjusted odds ratios (ORs) and their $95 \%$ confidence intervals (Cls) from logistic regression analysis. A gene-environment interaction analysis was performed. The effect of the apoE genotypes on survival from GC was explored by a Kaplan-Meier analysis and Cox proportional hazard regression model.

Results: Subjects carrying at least one apoE $\varepsilon 2$ allele have a significant $60 \%$ decrease of $G \mathrm{C}$ risk $(\mathrm{OR}=0.40,95 \% \mathrm{Cl}$ : $0.19-0.84)$ compared with $\varepsilon 3$ homozygotes. No significant interaction emerged between the $\varepsilon 4$ or $\varepsilon 2$ allele and environmental exposures, nor $\varepsilon 2$ or $\varepsilon 4$ alleles affected the median survival times, even after correcting for age, gender and stadium.

Conclusions: Our study reports for the first time a protective effect of the $\varepsilon 2$ allele against GC, that might be partly attributed to the higher antioxidant properties of $\varepsilon 2$ compared with the $\varepsilon 3$ or $\varepsilon 4$ alleles. Given the study's sample size, further studies are required to confirm our findings.
\end{abstract}

Keywords: Gastric cancer, Apolipoprotein E, Genetic epidemiology, Polymorphism, Gene-environment interaction

\section{Background}

Apolipoprotein E (ApoE) is a small glycoprotein that plays a major role in the blood clearance of cholesterolrich particles, known as remnant lipoproteins [1]. Besides its well-recognized role in lipid metabolism, ApoE has been shown to be involved in several pathophysiological processes, including antioxidant and immune activities, as well as a modulating effect on angiogenesis, tumor cell growth and metastasis induction [2]. The structural gene (19q13.2) for apoE is polymorphic with

\footnotetext{
*Correspondence: sboccia@rm.unicatt.it

'Institute of Hygiene, Università Cattolica del Sacro Cuore, Rome, Italy

${ }^{3}$ IRCCS San Raffaele Pisana, Rome, Italy

Full list of author information is available at the end of the article
}

two single nucleotide polymorphisms (SNPs) within the coding region resulting in three different alleles $(\varepsilon 2, \varepsilon 3$, $\varepsilon 4$ ) and six apoE genotypes (three homozygotes $\varepsilon 4 / \varepsilon 4$, $\varepsilon 3 / \varepsilon 3$ and $\varepsilon 2 / \varepsilon 2$, and three heterozygotes $\varepsilon 4 / \varepsilon 3$, $\varepsilon 3 / \varepsilon 2$, $\varepsilon 4 / \varepsilon 2$ ), each showing different receptor-binding abilities $[3,4]$. A meta-analysis reported a nearly linear relationship between apoE genotypes and the levels of total and LDL serum cholesterol (LDL-C) when the six genotypes are ordered as follows: $\varepsilon 2 / \varepsilon 2, \varepsilon 2 / \varepsilon 3, \varepsilon 2 / \varepsilon 4, \varepsilon 3 / \varepsilon 3, \varepsilon 3 / \varepsilon 4$, $\varepsilon 4 / \varepsilon 4$ [5]. In general, compared to the individuals with the $\varepsilon 3$ allele, levels of total and LDL-C tend to be lower for those with the $\varepsilon 2$ allele and higher for $\varepsilon 4$ carriers [6]. In the past two decades, cross-sectional and prospective studies have reported that low serum cholesterol levels 
are associated with higher non-cardiovascular risk, especially cancer risk [7-10], thus, subjects with low serum total cholesterol levels are more likely to suffer from cancer. To date, the exact reason for such finding remains still unclear. Different explanations can be given as: (i) this association could theoretically reflect a direct causal role of cholesterol in cancer etiology, or it be due (ii) to some confounding factors that cause both low cholesterol and cancer, or (iii) to 'reverse causation', as low cholesterol levels could simply be the effect of cancer rather than the cause [11].

To fully answer the question whether a causal relationship exists between low cholesterol level and cancer, an alternative epidemiologic approach named "Mendelian randomization" can be used to overcome the problem of reverse causality and confounding. According to this approach, a genetic variation (e.g., apoE) that serves as a robust proxy for an environmentally modifiable exposure (e.g., serum cholesterol level) can be used in order to make causal inferences about a disease [12]. Benn et al. [13] have recently showed that low LDL-C were robustly associated with cancer in a large Danish cohort study, while a reduction in LDL caused by SNPs, including apo $E$, was not. By adopting the Mendelian Randomization approach, Benn concluded that his results are in accordance with those emerged from a cohort of elderly subjects treated with pravastatin [14] and from the Atherosclerosis Risk in communities cohort study [15], all suggesting low LDL are probably due to the preclinical cancer stage and per se do not cause cancer.

The role of apoE genotypes on gastric cancer (GC) aetiology has not been exlpored so far, as Benn et al. [13] considered all gastrointestinal cancer with no specific focus on GC. To date, four cohort studies [10,16-18] explored the relationship between serum cholesterol level and the development of GC. Among them, two Japanese cohort studies $[10,18]$ and a Swedish study [16] reported that low serum cholesterol levels are independent risk factors for developing gastric cancer, especially the intestinal histotype. No association, however, was reported in a large Finnish cohort study [17]. Since the question of whether hypocholesterolemia is a predisposing factor for GC or a preclinical stage of GC has not been fully solved, our hospital-based casecontrol study aims to overcome this issue by directly looking at the relationship between $a p o E$ genotypes and GC as well as their interaction with potential effect modifiers.

\section{Results}

General characteristics of the study population including 156 GC cases and 444 controls are presented in Table 1. Alcohol consumption was associated with an increased $\mathrm{GC}$ risk with ORs of $1.84(95 \% \mathrm{CI}=1.10-3.07)$ and 3.29 (95\% CI $=1.36-7.98)$ for moderate and heavy drinkers,
Table 1 Odds ratios $(95 \% \mathrm{Cl})$ for gastric cancer according to selected variables and their frequency distribution among 156 gastric cancer cases and 444 controls

\begin{tabular}{|c|c|c|c|}
\hline & Cases & Controls & OR $(95 \% \mathrm{Cl}) \dagger$ \\
\hline & n (\%) & n (\%) & \\
\hline Age (mean $\pm S D)$ & $67.05 \pm 11.33$ & $59.04 \pm 16.00$ & \\
\hline Male gender & $82(53.2)$ & $261(58.8)$ & $0.50(0.30-0.83)$ \\
\hline \multicolumn{4}{|l|}{ Alcohol drinkers } \\
\hline 0-6 g/day & $60(40.5)$ & $251(57.6)$ & $1^{*}$ \\
\hline 7-29 g/day & $71(48.0)$ & $163(37.4)$ & $1.84(1.10-3.07)$ \\
\hline$>=30 \mathrm{~g} / \mathrm{day}$ & $17(11.5)$ & $22(5.0)$ & $3.29(1.36-7.98)$ \\
\hline \multicolumn{4}{|l|}{ Smoking status } \\
\hline Never & $78(50.7)$ & $238(54.2)$ & $1^{*}$ \\
\hline Ever & $76(49.3)$ & $201(45.8)$ & $1.51(0.94-2.45)$ \\
\hline \multicolumn{4}{|l|}{ Pack-years of smoking } \\
\hline 0 & $74(51.7)$ & $245(57.0)$ & $1^{*}$ \\
\hline $1-25$ & $31(21.7)$ & $111(25.8)$ & $1.40(0.78-2.50)$ \\
\hline$>25$ & 38 (26.6) & $74(17.2)$ & $1.95(1.06-3.60)$ \\
\hline \multicolumn{4}{|l|}{ Fruit and vegetables intake } \\
\hline High‡ & $41(27.5)$ & $116(27.2)$ & $1^{*}$ \\
\hline Low & $108(72.5)$ & $310(72.8)$ & $1.18(0.70-1.98)$ \\
\hline \multicolumn{4}{|l|}{ Grilled meat } \\
\hline Low $\wedge$ & $106(75.7)$ & $314(81.1)$ & $1^{*}$ \\
\hline High & $34(24.3)$ & $73(18.9)$ & $1.25(0.72-2.15)$ \\
\hline \multicolumn{4}{|l|}{ Physical activity } \\
\hline Any & 29 (18.6) & $93(20.9)$ & $1^{*}$ \\
\hline None & $127(81.4)$ & $351(79.1)$ & $0.81(0.45-1.45)$ \\
\hline \multicolumn{4}{|l|}{ Family history of cancer } \\
\hline No & $87(62.2)$ & $291(71.2)$ & $1^{*}$ \\
\hline $\begin{array}{l}\text { Family history of gastric } \\
\text { cancer }\end{array}$ & $10(7.1)$ & $14(3.4)$ & $3.14(1.17-8.44)$ \\
\hline $\begin{array}{l}\text { Family history of other } \\
\text { cancer }\end{array}$ & $43(30.7)$ & $104(25.4)$ & 1.09 (0.66- 1.81) \\
\hline
\end{tabular}

ApoE allele frequency

\begin{tabular}{ccc}
$\varepsilon 3$ & $130(85.5)$ & $322(80.1)$ \\
$\varepsilon 2$ & $8(5.3)$ & $39(9.7)$ \\
$\varepsilon 4$ & $14(9.2)$ & $41(10.2)$ \\
\hline
\end{tabular}

† OR adjusted by age, gender, alcohol consumption (as continuous variable), packyears of smoking, grilled meat consumption and familiy history of cancer. * reference category.

₹ at least three portions of fruit and vegetables per day.

$\wedge$ less than four times/month.

respectively. A nearly doubled $\mathrm{GC}$ risk $(\mathrm{OR}=1.95,95 \%$ CI: 1.06 - 3.60) was detected among individuals smoking more than 25 pack-years. In addition, family history of gastric cancer resulted to be associated with an increased GC risk (OR=3.14, 95\% CI: 1.17 - 8.44; Table 1). Table 2 shows the distribution of the six apoE genotypes among $\mathrm{GC}$ cases and controls, with the $\varepsilon 3 / \varepsilon 2$ genotype being less 
Table 2 Distribution of ApoE polymorphism among gastric cancer cases and controls

\begin{tabular}{|c|c|c|c|c|c|}
\hline & Cases ₹ & Controls^ $\wedge$ & All cases & Intestinal $(n=79)$ & Diffuse $(n=57)$ \\
\hline & n (\%) & n (\%) & OR $(95 \% \mathrm{Cl})^{\dagger}$ & OR $(95 \% \mathrm{Cl})^{\dagger}$ & OR $(95 \% \mathrm{Cl})^{\dagger}$ \\
\hline$\varepsilon 3 / \varepsilon 3$ & $109(71.71)$ & $253(62.94)$ & $1^{*}$ & $1^{*}$ & $1^{*}$ \\
\hline$\varepsilon 3 / \varepsilon 2$ & 15 (9.87) & $63(15.67)$ & $0.43(0.21-0.91)$ & $0.34(0.13-0.92)$ & $0.57(0.23-1.40)$ \\
\hline$\varepsilon 3 / \varepsilon 4$ & $27(17.76)$ & 75 (18.66) & $0.70(0.37-1.30)$ & $0.75(0.35-1.60)$ & $0.64(0.27-1.47)$ \\
\hline$\varepsilon 2 / \varepsilon 2$ & $0(0.00)$ & $5(1.24)$ & NC & NC & NC \\
\hline$\varepsilon 2 / \varepsilon 4$ & $1(0.66)$ & $5(1.24)$ & $1.25(0.10-15.10)$ & $2.54(0.21-31.17)$ & NC \\
\hline$\varepsilon 4 / \varepsilon 4$ & $0(0.00)$ & $1(0.25)$ & $\mathrm{NC}$ & NC & NC \\
\hline$\varepsilon 3 / \varepsilon 2$ or $\varepsilon 2 / \varepsilon 2$ & $15(12.10)$ & $68(21.18)$ & $0.40(0.19-0.84)$ & $0.31(0.11-0.83)$ & $0.53(0.21-1.30)$ \\
\hline$\varepsilon 3 / \varepsilon 4$ or $\varepsilon 4 / \varepsilon 4$ & $27(19.85)$ & $76(23.10)$ & $0.68(0.36-1.26)$ & $0.71(0.34-1.53)$ & $0.62(0.27-1.43)$ \\
\hline
\end{tabular}

f Apolipoprotein genotype was measured in 152 cases.

$\wedge$ Apolipoprotein genotype was measured in 402 controls.

† OR adjusted by age, gender, alcohol consumption (as continuous variable), packyears of smoking, grilled meat consumption and family history of gastric cancer. * Reference category.

NC: not calculable due to few many values.

frequently represented in cases $(9.87 \%)$ than in controls (15.67\%).

Frequency of apoE genotypes respected the HardyWeinberg Equilibrium (HWE) in the control group ( $p$-value $>0.05$, data not shown). From the multivariate analysis, individuals carrying at least one apoE $\varepsilon 2$ allele had a significant $60 \%$ decreased risk of GC (OR $=0.40,95 \%$ CI: $0.19-0.84)$ when compared with those homozygous for the wild-type $(\varepsilon 3 / \varepsilon 3)$ (Table 2$)$. When results were stratified according to tumour histology, the significant association between apoE $\varepsilon 2$ allele carriers and gastric cancer appeared to be limited to the intestinal type, with an OR of 0.31 (95\% CI: 0.11 - 0.83; Table 2). Quality controls showed 100\% concordance between Restriction Fragment Length Polymorphism (RFLP) method and DNA sequencing.

Results of the gene-environment interaction analysis are presented in Table 3 . No statistically significant interaction emerged between the $\varepsilon 4$ or $\varepsilon 2$ allele ( $p$-value for interaction $>0.05$ ), gender, age, alcohol consumption or fruit and vegetables intake.

Median survival time from gastrectomy was 19 months with no statistical significant differences for $a p o E \varepsilon 2$ or $\varepsilon 4$ allele carriers ( $p$-value of log-rank test $>0.05$ ), even when the analysis was restricted to 1 year and 2 years after surgical intervention (data not shown). Cox regression analysis showed no significant difference according to apoE after adjusting for age, gender, and stadium, even after stratifying by cancer histotype.

\section{Discussion}

Our case-control study of 156 gastric cancer cases and 444 hospital-based controls evaluated for the first time the effect of $a p o E$ genotypes and their interactions with selected demographic and lifestyle factors on the risk of gastric cancer among an Italian population. According to our results, the apoE $\varepsilon 2$ allele is associated with a $60 \%$ statistically significant decreased risk for GC when compared with the wild-type $\varepsilon 3$ allele. This protective effect was particularly strong for the intestinal histotype. We were unable, however, to detect significant interactions between apoE alleles and lifestyle factors. Additionally, apoE genotypes do not appear to influence the survival time after surgical intervention, even when the analysis was restricted to the specific tumor histotypes.

Before interpreting our results, some limitations of the study should be taken into account. Firstly, on the basis of the prevalence of the $a p o E$ alleles in our control population, this study has a priori $90 \%$ power to detect an OR of 0.40 for the effect of the apoE $\varepsilon 2$ allele (at 5\% significance level). The study's sample size limits the possibility to detect statistically significant gene-environment interactions, however, we need to increase the sample size in order to confirm our results. Secondly, data on serum cholesterol levels are not available in our study population, even though their utility would be limited in view of the fact such levels are affected by the cancer itself.

The effect of $a p o E$ genotypes has been previously investigated in relation to breast, colorectal, biliary tract, prostate, head and neck cancer, and haematological malignancies [19-24], with conflicting results. A recently published Mendelian randomization study addressed the unsolved question about the causal role of cholesterol in cancer etiology by examining if some SNPs including apoE, all linked to lifelong reduced plasma LDL-C, are causally related to an increased risk of cancer among two large Danish general population studies [13]. Results show an inverse relationship between cancer incidence or mortality and cholesterol levels, while no effect was demonstrated for the apoE alleles. Even with some limitations on the selected cohort, authors conclude that there is a substantial lack of causal effect of cholesterol on cancer risk including gastrointestinal cancers. Accordingly, the apparent contradiction between results 
Table 3 Interactions between apoE genotypes and selected demographic and lifestyle variables on GC risk

\begin{tabular}{|c|c|c|c|c|c|c|}
\hline \multirow[t]{2}{*}{ Variables } & \multirow[t]{2}{*}{ Cases } & \multirow[t]{2}{*}{ Controls } & Any e2 & \multirow[t]{2}{*}{ Cases } & \multirow[t]{2}{*}{ Controls } & \multirow{2}{*}{$\frac{\text { Any e4 }}{\text { OR }(95 \% ~ C l)^{\dagger}}$} \\
\hline & & & OR $(95 \% \mathrm{Cl})^{\dagger}$ & & & \\
\hline \multicolumn{7}{|l|}{ Gender } \\
\hline Female, e3/e3 & $51(34.69)$ & $96(65.31)$ & $1^{*}$ & $51(34.69)$ & $96(65.31)$ & $1^{*}$ \\
\hline Female, variant & $8(27.59)$ & $21(72.41)$ & $0.58(0.20-1.65)$ & $12(24.00)$ & $38(76.00)$ & $0.55(0.23-1.32)$ \\
\hline Male, e3/e3 & $57(26.64)$ & $157(73.36)$ & $0.48(0.27-0.88)$ & $57(26.64)$ & $157(73.36)$ & $0.49(0.27-0.89)$ \\
\hline Male, variant & 7 (12.96) & $47(87.04)$ & $0.49(0.11-2.18)$ & $14(26.92)$ & $38(73.08)$ & $1.52(0.44-5.27)$ \\
\hline$P$ value for interaction ${ }^{\circ}$ & & & 0.347 & & & 0.660 \\
\hline \multicolumn{7}{|l|}{ Age } \\
\hline$<60$ years, e3/e3 & $25(17.73)$ & $116(82.27)$ & $1^{*}$ & $25(17.73)$ & $116(82.27)$ & $1^{*}$ \\
\hline$<60$ years, variant & $4(12.50)$ & $28(87.50)$ & $0.35(0.07-1.68)$ & $7(21.21)$ & $26(78.79)$ & $0.70(0.18-2.66)$ \\
\hline$\geq 60$ years, e3/e3 & $84(38.01)$ & 137 (61.99) & $2.85(1.53-5.28)$ & $84(38.01)$ & 137 (61.99) & $2.84(1.54-5.26)$ \\
\hline$\geq 60$ years, variant & $11(21.57)$ & $40(78.43)$ & $1.24(0.21-7.26)$ & $20(28.57)$ & $50(71.43)$ & $0.97(0.21-4.36)$ \\
\hline$P$ value for interaction & & & 0.807 & & & 0.964 \\
\hline \multicolumn{7}{|l|}{ Alcohol drinking } \\
\hline Never, e3/e3 & $45(24.06)$ & $142(75.94)$ & $1^{*}$ & $45(24.06)$ & $142(75.94)$ & $1^{*}$ \\
\hline Never, variant & $5(12.50)$ & $35(87.50)$ & $0.29(0.08-1.04)$ & $12(18.18)$ & $54(81.82)$ & $0.62(0.28-1.37)$ \\
\hline Ever, e3/e3 & $64(36.57)$ & $111(63.43)$ & $1.59(0.88-2.86)$ & $64(36.57)$ & $111(63.43)$ & $1.46(0.81-2.62)$ \\
\hline Ever, variant & $10(23.26)$ & $33(76.74)$ & $1.78(0.37-8.50)$ & $15(40.54)$ & $22(59.46)$ & $1.28(0.35-4.66)$ \\
\hline$P$ value for interaction & & & 0.468 & & & 0.707 \\
\hline \multicolumn{7}{|l|}{ Smoking status } \\
\hline Never, e3/e3 & $54(29.03)$ & $132(70.97)$ & $1^{*}$ & $54(29.03)$ & $132(70.97)$ & $1^{*}$ \\
\hline Never, variant & $8(20.51)$ & $31(79.49)$ & $0.48(0.18-1.28)$ & $13(20.00)$ & $52(80.00)$ & $0.53(0.23-1.23)$ \\
\hline Ever, e3/e3 & $54(31.40)$ & $118(68.60)$ & $1.41(0.80-2.50)$ & $54(31.40)$ & $118(68.60)$ & $1.39(0.79-2.45)$ \\
\hline Ever, variant & $7(16.28)$ & $36(83.72)$ & $0.68(0.15-2.98)$ & $13(36.11)$ & $23(63.89)$ & $1.98(0.59-6.73)$ \\
\hline$P$ value for interaction & & & 0.609 & & & 0.271 \\
\hline \multicolumn{7}{|c|}{ Fruit and vegetables intake } \\
\hline Low, e3/e3 & $28(29.47)$ & $67(70.53)$ & $1^{*}$ & $28(29.47)$ & $67(70.53)$ & $1^{*}$ \\
\hline Low, variant & $2(9.09)$ & $20(90.91)$ & $0.14(0.02-0.87)$ & $9(32.14)$ & $19(67.86)$ & $0.84(0.28-2.49)$ \\
\hline High, e3/e3 & $78(31.08)$ & $173(68.92)$ & $1.17(0.61-2.23)$ & $78(31.08)$ & $173(68.92)$ & $1.12(0.59-2.13)$ \\
\hline High, variant & $11(19.30)$ & $46(80.70)$ & $2.83(0.38-21.05)$ & $16(22.86)$ & $54(77.14)$ & $0.62(0.16-2.37)$ \\
\hline$P$ value for interaction & & & 0.309 & & & 0.487 \\
\hline
\end{tabular}

† OR adjusted by age, gender, alcohol consumption (as continuous variable), packyears of smoking, grilled meat consumption and familiy history of gastric cancer. * Reference category.

- By likelihood ratio test.

relating plasma cholesterol levels and cancer risk with respect to apo $E$, might be indicative of a preclinical cancer stage involving the increased uptake of cholesterol from the blood for the cell growth and proliferation, thus lowering cholesterolemia prior to the clinical cancer diagnosis.

As for stomach cancer, two Japanese cohort studies $[10,18]$ and a Swedish cohort study [16] reported a strong inverse association between serum cholesterol levels and risk of gastric cancer. Japanese studies, however, found the association far less stronger after exclusion of the early 3-year incident cases and advanced cases, thus suggesting the development of stomach cancer itself tends to lower total cholesterol levels. To overcome the issues related to reverse causation or confounding by lifestyle factors, we decided to clarify the role of cholesterol levels on GC risk by using a Mendelian randomization approach, namely by studying directly the effect of the $a p o E$ genotypes on a large series of Italian GC cases and controls. Our results show a statistically significant $60 \%$ decreased risk of GC associated with the $\varepsilon 2$ allele.

Since $\varepsilon 2$ carriers have a lower serum cholesterolemia than non- $\varepsilon 2$ carriers, our finding contradicts the previously reported observation that low serum cholesterol levels 
increase GC risk [10,16,18]. ApoE, however, has many other functions beside its well-known role in lipid metabolism, that are potentially involved in cancer risk, as it is involved in tissue repair, inflammatory and immune response, cell growth and angiogenesis [2], and shows antioxidant properties [25]. Of importance, ApoE protein has certain antioxidative properties, with decreasing antioxidant activity in the order $\varepsilon 2>\varepsilon 3>\varepsilon 4$ alleles [25]. Even if the molecular mechanisms responsible for the antioxidant properties of $a p o E$ is not clarified yet, a number of studies have examined the mechanisms through which apoE genotypes could affect the oxidative status-dependent mediators or biomarkers of oxidative stress [26-28]. ApoE \&2-carrier smoking individuals, who are exposed to nicotine, an important source of oxidative stress, have an almost 30\% higher total antioxidant status compared with apoE ع3-carriers, measured as the capacity to inhibit the peroxidase-mediated formation of the 2,2-azino-bis-3-ethylbensthiazoline-6-sulfonic acid (ABTS+) radical, while apoE $\varepsilon 4$ subjects show a $30 \%$ increased oxidised LDL [26].

Oxidative stress is given by an imbalance between increased production of reactive oxygen species and a significant decrease in the capability of antioxidant functions. The production of peroxides and free radicals associated with changes in the normal redox state of tissues can induce toxic effects including oxidative DNA damage that along with hypoxia, and acidosis, might be greatly involved in the pathogenesis of GC as it can be considered the cause as well as the consequence of tumor progression [29,30]. Some evidence showed a wide magnitude of oxidative stress in GC cases if compared with healthy individuals, as demonstrated by elevated levels of lipid peroxidation products and depletion of enzymatic and non-enzymatic antioxidants [31,32]. In view of all these findings, the results of our study, which reports a protective effect of the apoE $\varepsilon 2$ allele on GC, might be explained by the improved antioxidant properties of $\varepsilon 2$ allele compared with the $\varepsilon 3$ or $\varepsilon 4$ alleles, and this evidence can be especially true for $\mathrm{GC}$, whose pathogenesis is strongly affected by smoking-related oxidative stress [33]. If our model holds true, we would expect an interaction between apoE $\varepsilon 2$ allele and smoking status, however the limited power of our interaction analysis may have obscured it.

\section{Conclusions}

In conclusion, our study provides for the first time evidence of a possible protective effect of the $\varepsilon 2$ allele against GC. Further studies are required to confirm our results and to figure out if the protective effect is mediated through lowered cholesterol level or better antioxidant properties.

\section{Methods}

\section{Study population}

The study subjects were selected according to a casecontrol study design as previously described [34-36]. Briefly, cases were consecutive primary gastric adenocarcinoma patients, with histological confirmation, who underwent a curative gastrectomy in the "A. Gemelli" teaching hospital during the period 2002-2010. Controls were selected from cancer-free patients, with a broad range of diagnoses, admitted to the same hospital during the identical time period.

In closer details, about $50 \%$ of our control population is made of blood donors while the other half is made of patients undergoing surgical interventions as laparoscopic cholecystectomy or appendicitis or inguinal hernia and a smaller portion of patients affected by chronic diseases as hypertension or Chronic Obstructive Pulmonary Disease (COPD) undergoing periodical check-up.

All subjects were Caucasians born in Italy. The study sample size comprised 156 cases and 444 controls, with a participation rate of $98 \%$ among cases and $93 \%$ among controls. According to Lauren classification, the majority (58.1\%) of gastric cancer cases were intestinal [37]. The tumours were located in the antrum (44.5\%), in the corpus $(14.8 \%)$, in the antrum/corpus (21.1\%), in the cardia $(3.1 \%)$, stumps $(5.5 \%)$, in the fundum $(1.6 \%)$, in the car$\mathrm{dia} /$ corpus (6.3\%) and the entire stomach (3.1\%). Based on the cytological and architectural atypisms, as well as the histo-pathological reports [38], patients' tumours were classified accordingly: $70.0 \%$ scarcely differentiated (G3), $27.6 \%$ moderately differentiated (G2), 3.4 \% welldifferentiated (G1), while $51.7 \%$ were staged I-II and $48.3 \%$ staged III-IV.

Written informed consent was obtained from all study subjects, after which each subject provided a venous blood sample that was collected into EDTA-coated tubes. This study was performed according to the Declaration of Helsinki and was approved by the ethics committee of the Università Cattolica del Sacro Cuore.

\section{Genotyping}

DNA was extracted from the peripheral blood lymphocytes, and genotyping of apoE was performed using Restriction Fragment Length Polymorphism (RFLP). Briefly, 20ng of genomic DNA amplified using oligonucleotide primers 5'-TCC AAG GAG CTG CAG GCG GCG CA-3' and 5'-GCC CCG GCC TGG TAC ACT GCC A-3'. Reactions were denatured for 3 minutes at $95^{\circ} \mathrm{C}$, followed by 35 two-step cycles consisting of 10 seconds at $95^{\circ} \mathrm{C}$ then 10 seconds at $66^{\circ} \mathrm{C}$. After the cycles were completed a final extension of 5 minutes at $95^{\circ} \mathrm{C}$ was performed. A $10 \mu \mathrm{l}$ aliquot of each RFLP product was digested with $5 \mathrm{U}$ of $A f l \mathrm{III}$ and a separate $10 \mu \mathrm{l}$ aliquot was digested with $5 \mathrm{U}$ of HaeII. Both apoE ع2 
and $a p o E \varepsilon 3$ alleles were cut with $A f l I I I$ to yield products of 50 and $168 \mathrm{bp}$, while the apoE $\varepsilon 4$ allele remains uncut at $218 \mathrm{bp}$. Using HaeII, both apoE ع3and apoE $\varepsilon 4$ alleles yield products of 23 and $195 \mathrm{bp}$, while the apoE $\varepsilon 2$ allele remains uncut at $218 \mathrm{bp}$. The six possible genotypes were assigned by analyzing the patterns produced by the restriction digest. As for the quality controls, $5 \%$ of the samples were also sequenced, with standard DNA samples for each apoE genotype sent by Seripa et al. [39].

\section{Data Collection}

Cases and controls were interviewed by trained medical doctors using a structured questionnaire to collect information on demographic data, cigarette smoking, drinking history, dietary habits, physical activity and family history of cancer with a special focus on gastric cancer. Participants were asked to focus on the year prior to diagnosis (for controls the year prior to the interview date) when answering questions regarding lifestyle habits. Smoking status was categorized as never and ever-smokers (including both current and former smokers). Pack-years were calculated as years smoked multiplied by the current number (or previous number, for those who had quit) of cigarettes smoked per day divided by 20 .

Fruit and vegetables intake was categorized as high if at least three portions of fruit and vegetables were consumed daily while grilled meat intake was defined as low if the consumption was less than 4 times/month. Family history of cancer referred to parents, siblings and offspring. Data concerning previous Helicobacter pylori infection were available only for gastric cancer cases. The response rate for completing the interview was $92 \%$ for cases and $97 \%$ for controls, with the exception of data relating to grilled meat intake (unknown in 10\% of cases and $12.8 \%$ of controls) and the family history of cancer (unknown in $10 \%$ of cases and $8 \%$ of controls).

\section{Statistical analysis}

The relationship between gastric cancer and putative risk factors were measured using the adjusted odds ratios (ORs) and their 95\% confidence interval (CI) derived from logistic regression analysis using STATA software (version 10.0). Possible risk factors were considered to be confounders if the addition of that variable to the model changed the OR by $10 \%$ or more, and once a confounder of any estimated main effect was identified, it was kept in all models. Based on these criteria, we controlled for age, gender, alcohol and grilled meat consumption, cigarette smoking (pack-years) and family history of gastric cancer. A $x^{2}$-test of Hardy-Weinberg Equilibrium (HWE) for the three apoE alleles was performed among controls. In order to examine if the effect of the selected polymorphisms was modified by some environmental exposures, a stratified logistic regression analysis was performed, adjusting for the confounders previously identified. A gene-environment interaction analysis was performed by using those carrying the homozygous wild-type genotype $(\varepsilon 3 / \varepsilon 3$ related to the $a p o E \varepsilon 3$ isoform) as the reference group. In this analysis, the genotypes were categorized as follows: presence of at least one $a p o E \varepsilon 2$ allele or presence of at least one apoE $\varepsilon 4$ allele (the genotype $\varepsilon 2 / \varepsilon 4$ was not included in either category), providing the other two apoE isoforms (apo $E 2$ and apo E4).

In this analysis, age was categorized binomially $(<60$ and $\geq 60$ years old), smoking status was considered as ever/never cigarette smokers, and alcohol consumption as drinkers/non-drinkers (the latter including individuals whose alcohol intake was less than $7 \mathrm{~g} /$ day). In order to test for interaction between two exposure variables, the likelihood ratio test was used, with the individuals homozygous for wild-type genotype $(\varepsilon 3 / \varepsilon 3)$ and not exposed to the variables of interest used as the reference group.

Overall survival curves were calculated by the KaplanMeier product limit method from the date of diagnosis until death. If a patient was not dead, survival was censored at the time of the last visit. The log rank test was used to assess differences between subgroups. The risk of death related to ApoE isoforms was estimated by Cox's proportional hazards model. Hazard ratios (HR) were adjusted for age, gender, and stadium, with the wild-type genotype $(\varepsilon 3 / \varepsilon 3)$ as the reference group. In addition, analyses were stratified according to cancer histotype (intestinal/diffuse).

\section{Abbreviations}

OR: Odds ratio; Cl: Confidence interval; HWE: Hardy-Weinberg Equilibrium; ApoE: Apolipoprotein E; GC: Gastric cancer; SNPs: Single nucleotide polymorphisms.

\section{Competing interests}

The authors declare they have no competing interests.

\section{Authors' contributions}

EDF, WR and SB conceived the study and implemented the final draft of the manuscript; EDF and BS performed the statistical analysis and wrote the paper; RP, AB, FC and DDU recruited gastric cancer cases and controls; DA and RA processed blood samples and genotyped for apoE. All authors read and approved the final manuscript.

\section{Source of support}

No funding support to be declared.

\section{Author details}

'Institute of Hygiene, Università Cattolica del Sacro Cuore, Rome, Italy.

${ }^{2}$ Department of Surgery, Università Cattolica del Sacro Cuore, Rome, Italy. ${ }^{3}$ IRCCS San Raffaele Pisana, Rome, Italy.

Received: 8 March 2012 Accepted: 11 October 2012

Published: 25 October 2012 


\section{References}

1. Mahley RW, Huang Y: Atherogenic remnant lipoproteins: role for proteoglycans in trapping, transferring, and internalizing. $J$ Clin Invest 2007, 17:94-98.

2. Vogel T, Guo NH, Guy R, et al: Apolipoprotein E: a potent inhibitor of endothelial and tumor cell proliferation. J Cell Biochem 1994, 54:299-308.

3. Moore LE, Brennan P, Karami S: Apolipoprotein E/C1 locus variants modify renal cell carcinoma risk. Cancer Res 2009, 69:8001-8008.

4. Mahley RW, Nathan BP, Pitas RE: Apolipoprotein E: Structure, function, and possible roles in Alzheimer's disease. Ann N Y Acad Sci 1996, 777:139-145.

5. Bennet AM, Di Angelantonio E, Ye Z, et al: Association of apolipoprotein E genotypes with lipid levels and coronary risk. JAMA 2007, 298:1300-1311.

6. Brouwers N, Sleegers K, Van Broeckhoven C: Molecular genetics of Alzheimer's disease: an update. Ann Med 2008, 40:562-583.

7. Jacobs D, Blackburn H, Higgins M, et al: Report of the Conference on Low Blood Cholesterol: Mortality Associations. Circulation 1992, 86:1046-1060.

8. Delahaye F, Bruckert E, Thomas D, Emmerich J, Richard JL: Serum cholesterol and cancer. Is there a casual relationship? Arch Mal Coeur Vaiss 1992, 85:37-45.

9. Forones NM, Falcao JB, Mattos D, Barone B: Cholesterolemia in colorectal cancer. Hepatogastroenterology 1998, 45:1531-1534.

10. Asano K, Kubo M, Yonemoto $K$, et al: Impact of serum total cholesterol on the incidence of gastric cancer in a population-based prospective study: the Hisayama study. Int J Cancer 2008, 122:909-914.

11. Kritchevsky SB, Kritchevsky D: Serum cholesterol and cancer risk: an epidemiologic perspective. Annu Rev Nutr 1992, 12:391-416.

12. Lawlor DA, Harbord RM, Sterne JA, Timpson N, Davey Smith G: Mendelian randomization: using genes as instruments for making causal inferences in epidemiology. Stat Med 2008, 27:1133-1163.

13. Benn M, Tybjærg-Hansen A, Stender S, Frikke-Schmidt R, Nordestgaard BG: Low-density lipoprotein cholesterol and the risk of cancer: a mendelian randomization study. J Natl Cancer Inst 2011, 103:508-519.

14. Trompet S, Jukema JW, Katan MB, et al: Apolipoprotein e genotype, plasma cholesterol, and cancer: a Mendelian randomization study. Am J Epidemiol 2009, 170:1415-1421.

15. Folsom AR, Peacock JM, Boerwinkle E: Sequence variation in protein convertase subtilisin/kexin type 9 serine protease gene, low LDL cholesterol, and cancer incidence. Cancer Epidemiol Biomarkers Prev 2007 16:2455-2458

16. Tornberg SA, Carstensen JM, Holm LE: Risk of stomach cancer in association with serum cholesterol and beta-lipoprotein. Acta Oncol 1988, 27:39-42.

17. Knekt P, Reunanen A, Aromaa A, Heliovaara M, Hakulinen T, Hakama M: Serum cholesterol and risk of cancer in a cohort of 39,000 men and women. J Clin Epidemiol 1988, 41:519-530

18. Iso H, Ikeda A, Inoue M, Sato S, Tsugane S, for the JPHC Study Group: Serum cholesterol levels in relation to the incidence of cancer: The JPHC study cohorts. Int J Cancer 2009, 125:2679-2686.

19. Mrkonjic M, Chappell E, Pethe W, et al: Association of apolipoprotein E polymorphisms and dietary factors in colorectal cancer. Br J Cancer 2009, 100:1966-1974.

20. Slattery ML, Sweeney C, Murtaugh M, et al: Associations between apoE genotype and colon and rectal cancer. Carcinogenesis 2005, 26:1422-1429

21. Chang NW, Chen DR, Wu CT, et al: Influences of apolipoprotein E polymorphism on the risk for breast cancer and HER2/neu status in Taiwan. Breast Cancer Res Treat 2005, 90:257-261.

22. Andreotti G, Chen J, Gao YT, et al: Polymorphisms of genes in the lipid metabolism pathway and risk of biliary tract cancers and stones: a population-based case-control study in Shanghai, China. Cancer Epidemiol Biomarkers Prev 2008, 17:525-534.

23. Schatzkin A, Hoover RN, Taylor PR, et al: Site-specific analysis of total serum cholesterol and incident cancers in the National Health and Nutrition Examination Survey I epidemiologic follow-up study. Cancer Res 1998, 48:452-458.

24. De Feo E, Rowell J, Cadoni G, Nicolotti N, Arzani D, Giorgio A, Amore R, Paludetti G, Ricciardi G, Boccia S: A case-control study on the effect of apoliprotein E genotype on head and neck cancer risk. Cancer Epidemiol Biomarkers Prev 2010, 19:2839-2846.
25. Jofre-Monseny LO, Minihane AM, Rimbach G: Impact of apoE genotype on oxidative stress, inflammation and disease risk. Mol Nutr Food Res 2008, 52:131-145

26. Talmud PJ, Stephens JW, Hawe E, et al: The significant increase in cardiovascular disease risk in ApoE4 carriers is evident only in men who smoke: Potential relationship between reduced antioxidant status and ApoE4. Ann Hum Genet 2005, 69:613-622.

27. Dietrich $M$, Hua $Y$, Block $G$, et al: Associations between apolipoprotein $E$ genotype and circulating F2- isoprostane levels in humans. Lipids 2005, 40:329-334.

28. Tsuda M, Sanada M, Nakagawa H, Kodama I, Sakashita T, Ohama K: Phenotype of apolipoprotein $\mathrm{E}$ influences the lipid metabolic response of postmenopausal women to hormone replacement therapy. Maturitas 2001, 38:297-304.

29. Xie K, Huang S: Regulation of cancer metastasis by tumor associated stress factors. Clin Exp Metastasis 2003, 20:31-43.

30. Suzuki H, Nishizawa T, Tsugawa H, Mogami S, Hibi T: Roles of oxidative stress in stomach disorders. J Clin Biochem Nutr 2012, 50:35-39.

31. Pasupathi P, Saravanan G, Chinnaswamy P, Bakthavathsalam G: Effect of chronic smoking on lipid peroxidation and antioxidant status in gastric carcinoma patients. Indian J Gastroenterol 2009, 28:65-67.

32. Kekec Y, Paydas S, Tuli A, Zorludemir S, Sakman G, Seydaoglu G: Antioxidant enzyme levels in cases with gastrointesinal cancer. Eur J Intern Med 2009, 20:403-406.

33. Oh SS, Chang SC, Cai L, Cordon-Cardo C, Ding BG, Greenland S, He N, Jiang Q, Kheifets L, Le A, Lee YC, Liu S, Lu ML, Mao JT, Morgenstern H, Mu LN, Pantuck A, Papp JC, Park SL, Rao JY, Reuter VE, Tashkin DP, Wang H, You NC, Yu SZ, Zhao JK, Belldegrun A, Zhang ZF: Single nucleotide polymorphisms of 8 inflammation-related genes and their associations with smoking-related cancers. Int J Cancer 2010, 127:2169-2182.

34. Boccia S, Gianfagna F, Persiani R, La Greca A, Arzani D, Rausei S, D'ugo D, Magistrelli P, Villari P, Van Duijn CM, Ricciardi G: Methylenetetrahydrofolate reductase $\mathrm{C} 677 \mathrm{~T}$ and $\mathrm{A} 1298 \mathrm{C}$ polymorphisms and susceptibility to gastric adenocarcinoma in an Italian population. Biomarkers 2007, 12:635-644.

35. Boccia S, Sayed-Tabatabaei FA, Persiani R, Gianfagna F, Rausei S, Arzani D, La Greca A, D'Ugo D, La Torre G, van Duijn CM, Ricciardi G: Polymorphisms in metabolic genes, their combination and interaction with tobacco smoke and alcohol consumption and risk of gastric cancer: a case-control study in an Italian population. BMC Cancer 2007, 7:206.

36. De Feo E, Persiani R, La Greca A, Amore R, Arzani D, Rausei S, D'Ugo D, Magistrelli $P$, van Duijn CM, Ricciardi G, Boccia S: A case-control study on the effect of $p 53$ and $p 73$ polymorphisms on gastric cancer risk and progression in an Italian population. Mutat Res 2009, 675:60-65.

37. Lauren P: The two histological main types of gastric carcinoma: diffuse and so called intestinal-type carcinoma. An attempt at a histo-clinical classification. Acta Pathol Microbiol Scand 1965, 64:31-49.

38. Sobin LH, Wittekind C: TNM classification of malignant tumors, UICC. New York: Wiley-Liss; 2002

39. Seripa D, Signori E, Gravina C, Matera MG, Rinaldi M, Fazio VM: Simple and effective determination of apolipoprotein E genotypes by positive/ negative polymerase chain reaction products. Diagn Mol Pathol 2006, 15:180-185.

doi:10.1186/1471-2407-12-494

Cite this article as: De Feo et al:: A case-control study on the effect of Apolipoprotein $\mathrm{E}$ genotypes on gastric cancer risk and progression. BMC Cancer 2012 12:494. 